\title{
Correlation between Occupational Stress, Lifestyle, and Hyperglycemia among Obese and Non-Obese Middle-Aged Japanese Male Workers
}

\author{
Itsuko Bonkohara ${ }^{*}$, Yoko Kubo² ${ }^{2}$, Toshio Kobayashi ${ }^{3}$ \\ ${ }^{1}$ Department of Clinical Nursing Study, Faculty of Nursing, Yasuda Women's University, Hiroshima, Japan \\ ${ }^{2}$ Psychiatric and Mental Health Nursing, University of Occupational and Environmental Health, Kitakyushu, \\ Japan \\ ${ }^{3}$ Department of Health Development, Institute of Biomedical \& Health Sciences, Hiroshima University, \\ Hiroshima, Japan \\ Email: "bonkohara@yasuda-u.ac.jp, sunchaild@health.uoeh-u.ac.jp, tkobaya@hiroshima-u.ac.jp
}

Received 15 July 2016; accepted 21 August 2016; published 24 August 2016

Copyright (C) 2016 by authors and Scientific Research Publishing Inc.

This work is licensed under the Creative Commons Attribution International License (CC BY).

http://creativecommons.org/licenses/by/4.0/

(c) (i) Open Access

\section{Abstract}

The aim of this study was to identify the correlation between stress, lifestyle, and hyperglycemia among middle-aged Japanese male workers. We also analyzed the obese (OB) and non-obese (non$\mathrm{OB})$ groups pertaining to the risk of hyperglycemia. A total of 353 male employees aged between 50 and 59 years taking health checkup sat a company in Japan were examined. The data were collected using validated scales of occupational stress and medical examination. Of the $353 \mathrm{em}$ ployees, 335 (effective response rate $95 \%$ ) were analyzed. "Support from colleagues" and "reward from work" reported by the OB group were lower than the non-OB group. The items "eating until satiety" and "having greasy meal often" were significantly more common in the OB group than in the non-OB group. There was a significant correlation between less sleep time and hyperglycemia in the $O B$ group than in the non-OB group. The non-OB group reported more overtime hours than the OB group. Hyperglycemia in the non-OB group was positively correlated with long working hours, "workload," and "mental workload." The results indicated that the OB group would benefit from lifestyle interventions, for example, improvement in sleep time and eating habits may prevent hyperglycemia and eventually in obesity. Furthermore, it was suggested that stress in response to "workload" and "mental workload" owing to long working hours leads to hyperglycemia in the non-OB group. Therefore, the improvement of the workplace environment, reducing the number of hours at work, and stress management are required to prevent hyperglycemia in the

\footnotetext{
${ }^{*}$ Corresponding author.
} 


\section{non-OB group.}

\section{Keywords}

\section{Hyperglycemia, Obesity, Occupational Stress, Japanese Male Workers}

\section{Introduction}

According to the 2012 National Health and Nutrition Examination Survey Overview of the Ministry of Health, Labor and Welfare of Japan [1], approximately 20,500,000 people who may develop diabetes, and 9,500,000 are considered to be suspected diabetes in Japan.

Obesity may be associated with the onset of diabetes; therefore, weight control is important for the prevention of diabetes among middle-aged people [2]. Since 2008, specific health checkups (specific medical examinations) for the early detection of metabolic syndrome (MetS) have been conducted to provide guidance regarding health and living habits [3] [4]. Early intervention in MetS to prevent its progression to diabetes and cardiovascular diseases is an important step in curbing the rise in the national medical expenses.

However, there is a risk that the number of non-obese (non-OB) diabetic patients with cardiovascular metabolic markers may increase [5]. Hyperglycemia, high blood pressure, and lipid metabolism abnormalities have been reported as risk factors for the development of cardiovascular disease [6] [7]. Therefore, we reviewed the specific health diagnoses and health guidance pertaining to obese (OB) subjects from 2013 and evaluated the incidence of hyperglycemia among non-OB subjects [1]. Stress can result from poor glycemic control in patients with diabetes, and when combined with occupation-related life-style, it can promote the onset of diabetes and associated complications [8]. Various stress levels have been reported to be strongly associated with the severity of diabetes [9].

In addition, it has been reported that the introduction of excessive overtime and new technologies may be risk factors for the development of diabetes [8], and a correlation between stressful situations with harsh working conditions and glycated hemoglobin levels has been demonstrated [9] [10].

The aim of this study was to verify the correlation between lifestyle and fasting blood glucose levels among $\mathrm{OB}$ and non-OB male workers in their fifties experiencing occupational stress.

\section{Subjects and Methods}

\subsection{Subjects}

A total of 356 male employees (age, 50 - 59 years) of a chemical manufacturing company in a rural city in Japan, 353 employees underwent regular health checkups in 2007, were surveyed.

\subsection{Survey Content}

The parameters of the survey included blood tests (blood sugar and HbA1c), subject characteristics [height, weight, body mass index (BMI), and waist circumference] collected according to medical records, and lifestyle habits (sleep duration, smoking history, alcohol consumption, overtime hours, and occupational stress status) collected by questionnaire survey. These parameters are discussed in detail below.

\subsection{Items for Blood Test, Subject Characteristics, and Lifestyle Habits}

Of the periodic health examination items, height, weight, BMI, waist circumference, and fasting blood sugar level were used for analysis. For lifestyle assessment, the following set of data were obtained: "alcohol consumption in 1 week," "average daily number of cigarettes smoked," "previous month's overtime hours," "average daily sleep duration,” "eating until satiety," "having greasy meal often,” and "eating out often.”

\subsection{Occupational Stress}

The occupational stress scale used in this study was created by Nishikido et al. [11] (2000) and was composed 
of 20 items comprising the following six subscales: “workload," "mental workload,” "job control,” "problems in personal relationships," "support from colleagues," and "rewards from work." Each subscale was graded on a scale of 1 - 4. The degree of stress was measured using the total score that was obtained in this survey and the average score for each subscale was calculated. A Cronbach's alpha in the range of $0.77-0.92$ was considered to be a stable measure of the coefficient of reliability for each subscale.

\subsection{Methods of Analysis}

Anonymous regular health checkup data obtained by the researchers were analyzed. Characteristics of the non-OB (waist circumference, $<85 \mathrm{~cm}$ ), OB (waist circumference, $>85 \mathrm{~cm}$ ), normoglycemic (fasting blood sugar level, $<110 \mathrm{mg} / \mathrm{dL}$ ), and hyperglycemic (fasting blood sugar level, $>110 \mathrm{mg} / \mathrm{dL}$ ) groups were compared using the chi-square test. The Mann-Whitney U-test was used to compare demographic data and blood sugar levels according to extent of obesity among groups. Then, based on the presence or absence of hyperglycemia in the obesity groups, the Spearman's rank correlation coefficient was used to assess the relationship between stress and lifestyle. A probability (p) value of $<0.05$ was considered statistically significant. All statistical analyses were performed using SPSS ver. 22.0 statistical software for Windows.

\section{Ethical Considerations}

The Research Ethics Committee of Hiroshima University (Hiroshima, Japan) approved the study protocol (approval number: 223). Completed questionnaire surveys were anonymously submitted. Subjects provided informed consent after receiving explanations regarding the purpose and significance of the study, privacy protection, data handling, and the manner in which the research results would be reported.

\section{Results}

\subsection{Subject Characteristics}

Comparisons of participant background data among groups are presented in "Table 1". Of a total of 353 male employees (aged, 50 - 59 years) who underwent regular health checkups in 2007, 17 having missing values in the questionnaire and 1 subject showing the outlying value of blood sugar were excluded. Therefore, a total of 335 employees (effective response rate, 95\%) were included for analysis.

There were significant differences in the fasting glucose level ( $97.4 \pm 12.4$ vs. $101.4 \pm 12.2 \mathrm{mg} / \mathrm{dL}$ ), height $(167.8 \pm 5.2$ vs. $169.8 \pm 5.9 \mathrm{~cm})$, weight $(62.5 \pm 6.5$ vs. $73.8 \pm 5.5 \mathrm{~kg})$, BMI $\left(22.2 \pm 2.1 \mathrm{vs.} 25.5 \pm 1.9 \mathrm{~kg} / \mathrm{m}^{2}\right)$, and waist circumference ( $77.4 \pm 5$ vs. $88.3 \pm 3.2 \mathrm{~cm}$ ) between the OB and non-OB groups, respectively; however, no significant difference in age ( $56.0 \pm 1.9$ vs. $56.0 \pm 1.7$ years) was observed between the OB and non-OB groups, respectively.

All the subjects graduated from high school or university, and their job categories were $14.6 \%$ of clerical staffs, $12.0 \%$ of research staffs and $73.4 \%$ of the manufacturing staffs, respectively. There was no difference in educational background and job categories between the OB and non-OB groups.

Table 1. Comparison of participant background data between obese and non-obese groups $(n=335)$.

\begin{tabular}{|c|c|c|c|c|c|}
\hline \multirow{2}{*}{ Variable } & \multicolumn{2}{|c|}{ OB $(n=96)$} & \multicolumn{2}{|c|}{ non-OB $(\mathrm{n}=239)$} & \multirow{2}{*}{ p-value } \\
\hline & mean & $\mathrm{SD}$ & mean & SD & \\
\hline Average age (years) & 56.0 & 1.7 & 56.0 & 1.9 & $\mathrm{p}=0.82$ \\
\hline Fasting blood sugar level (mg/dL) & 101.4 & 12.2 & 97.4 & 12.4 & $\mathrm{p}<0.01$ \\
\hline HbA1c (\%) & 5.2 & 0.7 & 5.1 & 0.5 & $\mathrm{p}=0.22$ \\
\hline Height (cm) & 169.8 & 5.9 & 167.8 & 5.2 & $\mathbf{p}<0.01$ \\
\hline Weights (kg) & 73.8 & 5.5 & 62.5 & 6.5 & $\mathrm{p}<0.01$ \\
\hline $\operatorname{BMI}\left(\mathrm{kg} / \mathrm{m}^{2}\right)$ & 25.6 & 1.9 & 22.2 & 2.1 & $\mathbf{p}<0.01$ \\
\hline Waist circumference (cm) & 88.3 & 3.2 & 77.4 & 5.0 & $\mathrm{p}<0.01$ \\
\hline
\end{tabular}

Mann-Whitney U-value Calculator. OB: obese. 


\subsection{Comparison of Stress and Lifestyle between the OB and Non-OB Groups}

Comparisons of stress and lifestyle between the OB and non-OB groups are shown in "Table 2". Regarding stress status, the responses to "support from colleagues" and "rewards from work" were significantly lower in the OB group than in the non-OB group $(2.53 \pm 0.62$ vs. $2.70 \pm 0.56, \mathrm{p}<0.05$ and $2.42 \pm 0.66$ vs. $2.62 \pm 0.62$, p $<0.05$, respectively).

Average overtime for the previous month was significantly higher in the non-OB group than in the OB group $(14.1 \pm 17.1$ h vs. $10.8 \pm 14.6$ h, respectively; $\mathrm{p}<0.05)$. Subjects in the OB group had a significantly shorter sleep duration than those in the non-OB group $(6.9 \pm 0.8$ vs. $7.1 \pm 0.9 \mathrm{~h} ; \mathrm{p}<0.05)$.

\subsection{Eating Habits in the $O B$ and Non-OB Groups}

Eating habits of the subjects in the OB and non-OB groups are presented in "Table 3”. Significantly more subjects in the OB group answered "yes" to the items "eating until satiety," and "having greasy meals often," as compared with those in the non-OB group $(\mathrm{p}<0.05)$.

\subsection{The Prevalence of Normoglycemia and Hyperglycemia in the $\mathrm{OB}$ and Non-OB Groups}

The prevalence of normoglycemia and hyperglycemia in the OB and non-OB groups is shown in "Table 4". Of the 96 employees in the OB group, 75 (78.1\%) had normoglycemia and 21 (21.9\%) had hyperglycemia. Of the

Table 2. Comparison of stress and lifestyle habits between obese and non-obese groups $(n=335)$.

\begin{tabular}{|c|c|c|c|c|c|}
\hline \multirow{2}{*}{ Variable } & \multicolumn{2}{|c|}{ OB $(n=96)$} & \multicolumn{2}{|c|}{ non-OB $(\mathrm{n}=239)$} & \multirow{2}{*}{ p-value } \\
\hline & mean & SD & mean & SD & \\
\hline \multicolumn{6}{|l|}{ Stress $^{\mathrm{a}}$} \\
\hline Workload & 1.95 & 0.69 & 1.89 & 0.67 & $\mathrm{p}=0.48$ \\
\hline Mental workload & 1.88 & 0.7 & 1.77 & 0.61 & $\mathrm{p}=0.29$ \\
\hline Job control & 2.51 & 0.65 & 2.59 & 0.59 & $p=0.63$ \\
\hline Problem in personal relationship & 1.62 & 0.54 & 1.62 & 0.56 & $\mathrm{p}=0.96$ \\
\hline Support from colleagues & 2.53 & 0.62 & 2.7 & 0.56 & $p=0.04$ \\
\hline Reward from work & 2.42 & 0.66 & 2.62 & 0.62 & $p=0.03$ \\
\hline \multicolumn{6}{|l|}{ Lifestyle } \\
\hline The amount of drinking for 1 week (g) & 180.4 & 149.7 & 194.2 & 171.8 & $\mathrm{p}=0.74$ \\
\hline 1-day average smoking number & 9.6 & 12.7 & 10.1 & 12.3 & $\mathrm{p}=0.71$ \\
\hline Overtime for the previous month (h) & 10.8 & 14.6 & 14.1 & 17.1 & $p=0.04$ \\
\hline 1-day average sleeping hours (h) & 6.9 & 0.8 & 7.1 & 0.9 & $p=0.03$ \\
\hline
\end{tabular}

a: Stress; score range, 1 - 4. Mann-Whitney U-value Calculator. OB: obese.

Table 3. Comparison of eating habits between obese and non-obese groups $(n=335)$.

\begin{tabular}{|c|c|c|c|c|c|}
\hline \multicolumn{2}{|c|}{ Variable } & \multirow{2}{*}{$\begin{array}{c}\text { No (\%) } \\
74(77.1)\end{array}$} & \multirow{2}{*}{$\begin{array}{c}\text { Yes (\%) } \\
22(22.9)\end{array}$} & \multirow{2}{*}{$\begin{array}{l}\text { Total (\%) } \\
96(100)\end{array}$} & \multirow{3}{*}{$\begin{array}{l}\mathrm{p} \text {-value } \\
\mathbf{p}=\mathbf{0 . 0 2}\end{array}$} \\
\hline \multirow{2}{*}{ Eat until satiety } & OB (96) & & & & \\
\hline & non-OB (239) & 210 (87.9) & $29(12.1)$ & $239(100)$ & \\
\hline \multirow{2}{*}{ Greasy meal often } & OB (96) & $80(83.3)$ & $16(16.7)$ & $96(100)$ & \multirow{2}{*}{$p=0.03$} \\
\hline & non-OB (239) & 219 (91.6) & $20(8.4)$ & $239(100)$ & \\
\hline \multirow{2}{*}{ Eating out often } & OB (96) & 79 (82.3) & $17(17.7)$ & $96(100)$ & \multirow{2}{*}{$\mathrm{p}=0.06$} \\
\hline & non-OB (239) & 216 (90.4) & $23(9.6)$ & 239 (100) & \\
\hline
\end{tabular}

Fisher's direct method of chi-square test. OB: obese. 
239 employees in the non-OB group, 209 (87.4\%) had normoglycemia and 30 (12.6\%) had hyperglycemia. Hyperglycemia was significantly more prevalent in the OB group $\left(\chi^{2}=4.612, \mathrm{p}<0.05\right)$ than the non-OB group.

\subsection{Correlation between Stress and Lifestyle Habits among Subjects with Hyperglycemia in the $\mathrm{OB}$ and Non-OB Groups}

Correlation between stress and lifestyle habits among subjects with hyperglycemia in the OB and non-OB groups is shown in "Table 5". Among subjects with hyperglycemia in the OB group, there was a negative correlation between "mental workload" and "average daily number of cigarettes smoked" $(\mathrm{r}=-0.51, \mathrm{p}<0.05)$. On the other hand, among subjects with hyperglycemia in the non-OB group, there was a significant correlation between "overtime hours in the previous month," "workload" $(\mathrm{r}=0.64, \mathrm{p}<0.01)$, "mental workload," $(\mathrm{r}=0.45$, $\mathrm{p}<0.05)$, and "problems in personal relationship" $(\mathrm{r}=0.39, \mathrm{p}<0.05)$.

\section{Discussion}

In this study, we identified the correlation of stress and lifestyle with the prevalence of normoglycemia and hyperglycemia between OB and non-OB male workers (age, 50 - 59 years) of a chemical manufacturing company in Japan. OB was strongly correlated with hyperglycemia, suggesting that OB was a factor responsible for the development of hyperglycemia. Based on the report, more than $90 \%$ of OB subjects are at a high risk of type 2 diabetes [12]. Furthermore, the findings of this study suggested a strong correlation between obesity and high blood sugar.

In this study, the number of hours of sleeping was less in the OB subjects than the non-OB subjects. The report stated that sleep deprivation decreases the secretion of leptin, which is known to increase energy consumption and suppress appetite. Conversely, lack of sleep increases the secretion of ghrelin, which enhances appetite and has been reported to increase the degree of obesity [13]-[16]. Therefore, it is necessary for OB individuals to adopt a lifestyle that can improve sleeping habits.

Table 4. The prevalence of nomoglycemia and hyperglycemia in obese and non-obese groups $(\mathrm{n}=335)$.

\begin{tabular}{ccccc}
\hline Variable & Normoglycemia (\%) & Hyperglycemia (\%) & Total (\%) & p-value \\
\hline OB $(\mathrm{n}=96)$ & $75(78.1)$ & $21(21.9)$ & $96(100)$ & $\mathbf{p}=\mathbf{0 . 0 4}$ \\
non-OB $(\mathrm{n}=239)$ & $209(87.4)$ & $30(12.6)$ & $239(100)$ & $335(100)$ \\
Total & $284(84.8)$ & $51(15.2)$ & \\
\hline
\end{tabular}

Chi-square test. $\chi^{2}=4.612$, OB: obese.

Table 5. Correlation between stress and lifestyle habits among subjects with hyperglycemia in obese and non-obese groups $(n=51)$.

\begin{tabular}{|c|c|c|c|c|c|c|c|c|}
\hline \multirow[b]{2}{*}{ Variable } & \multicolumn{4}{|c|}{ OB $(n=21)$} & \multicolumn{4}{|c|}{ non-OB $(n=30)$} \\
\hline & $\begin{array}{l}\text { The amount } \\
\text { of drinking } \\
\text { for } 1 \text { week }\end{array}$ & $\begin{array}{c}\text { 1-day } \\
\text { average } \\
\text { smoking } \\
\text { number }\end{array}$ & $\begin{array}{c}\text { Overwork } \\
\text { the previous } \\
\text { month }\end{array}$ & $\begin{array}{l}\text { 1-day } \\
\text { average } \\
\text { sleeping } \\
\text { hours }\end{array}$ & $\begin{array}{l}\text { The amount } \\
\text { of drinking } \\
\text { for } 1 \text { week }\end{array}$ & $\begin{array}{c}\text { 1-day } \\
\text { average } \\
\text { smoking } \\
\text { number }\end{array}$ & $\begin{array}{c}\text { Overwork } \\
\text { the previous } \\
\text { month }\end{array}$ & $\begin{array}{c}\text { 1-day } \\
\text { average } \\
\text { sleeping } \\
\text { hours }\end{array}$ \\
\hline \multicolumn{9}{|l|}{ Stress } \\
\hline Workload & -0.18 & -0.33 & 0.17 & -0.24 & -0.10 & 0.25 & $0.64^{* *}$ & -0.23 \\
\hline Mental workload & 0.09 & $-0.51^{*}$ & 0.07 & -0.19 & -0.28 & 0.27 & $0.45^{*}$ & 0.03 \\
\hline Job control & 0.10 & 0.16 & 0.17 & -0.11 & -0.31 & 0.03 & -0.12 & 0.08 \\
\hline Problems in personal relationship & -0.12 & -0.18 & 0.10 & 0.12 & -0.32 & -0.06 & $0.39^{*}$ & -0.01 \\
\hline Support from colleagues & 0.18 & -0.16 & 0.10 & -0.28 & 0.22 & -0.10 & -0.09 & -0.01 \\
\hline Reward from work & 0.29 & 0.29 & 0.17 & 0.05 & -0.025 & -0.13 & 0.01 & 0.04 \\
\hline
\end{tabular}

Spearman's rank correlation coefficient. ${ }^{*} p<0.05$ and ${ }^{* *} p<0.01$ OB: obese. 
The OB group was more likely to respond positively to "eat until satiety," "greasy meal often,” and "eat out often," indicating poor dietary habits. This suggests a change in appetite-inhibiting hormone levels owing to lack of sleep. As a result, it is important for a person to understand that eating until satiety is not ideal and that refraining from eating out can prevent the onset of obesity [17].

Approximately $60 \%$ of patients with diabetes are reportedly not OB [5]. Chan [18] reported that Asians are at higher risk of developing type 2 diabetes in comparison with Europeans. Asians are more likely to develop the disease even at a lower BMI. This means that even if obesity is not present, the risk of developing diabetes may be high in the Japanese. Clinical observations by Tanabe [19] indicated the benefits of educating those at risk of hyperglycemia who are not yet overweight.

In this study, subjects with hyperglycemia in the non-OB group performed significantly more overtime work and reported more stress, including "workload" and "mental workload," than subjects with hyperglycemia in the non-OB group. If continuous chronic stress persists, noradrenaline is constantly secreted followed by tension and suffering. If tension continues, sympathetic hyperactivity continues and pancreatic cells are damaged because of excessive active oxygen. Therefore, this condition is further considered to cause hyperglycemia [20]. Then, high "work-load" promotes chronic stress action and suggests that it is easy to develop hyperglycemia.

By this study, it is suggested that the main causes underlying hyperglycemia in the OB and non-OB groups are different. OB group revealed that hyperglycemia may occur because of lack of sleep and the related lifestyle. On the other hand, non-OB group revealed that hyperglycemia may occur because of stress owing to long work hours.

\section{Conclusion}

The results of this study suggest that obesity leads to hyperglycemia. Sleep duration was significantly shorter in the OB group than in the non-OB group in this study. Hence, the OB group would likely benefit from lifestyle interventions such as improvement in sleep patterns and eating habits to prevent hyperglycemia and eventual obesity. For non-OB people, it has been suggested that stress, including "workload" and "mental workload" because of long work hours can lead to hyperglycemia. Therefore, improvement of the workplace environment, reducing the work hours, and stress and stress management, are required in order to prevent hyperglycemia.

\section{Acknowledgements}

The authors would like to thank the participants and directors of a chemical manufacturing company. This study was not supported by any funding.

\section{Conflict of Interest}

The authors declare that they have no conflict of interest.

\section{References}

[1] L.A.W. Ministry of Health (2012) Health Japan 21 (the Second Term), about the 2012 National Health and Nutrition Survey Results (in Japanese). http://www.mhlw.go.jp/bunya/kenkou/eiyou/dl/h24-houkoku.pdf

[2] Atik, D., Atik, C. and Karatepe, H. (2014) Metabolic Syndrome in Patients Undergoing Coronary Angiography. Acta Informatica Medica, 22, 360-364. http://dx.doi.org/10.5455/aim.2014.22.360-364

[3] L.A.W. Ministry of health (2009) White Papers \& Reports Annual Health, Labour and Welfare Report 2008-2009, 07 Specific Health Checkups and Specific Health Guidance. http://www.mhlw.go.jp/english/wp/wp-hw3/02.html

[4] Yamamoto, H. (2008) Health Checkups and Healthcare Advice with a Particular Focus on the Metabolic Syndrome in the Health Care System Reform. Journal of the National Institute of Public Health, 57, 3-8. (In Japanese with English Abstract)

[5] Kashima, S., Inoue, K., Matsumoto M. and Akimoto, K. (2014) Prevalence and Characteristics of Non-Obese Diabetes in Japanese Men and Women: The Yuport Medical Checkup Center Study. Journal of Diabetes, 7, 523-530. http://dx.doi.org/10.1111/1753-0407.12213

[6] Wilson, P.W., D’Agostino, R.B., Levy, D., Belanger, A.M., Silbershatz, H., and Kannel, W.B. (1998) Prediction of Coronary Heart Disease Using Risk Factor Categories. Circulation, 97, 1837-1847.

http://dx.doi.org/10.1161/01.CIR.97.18.1837 
[7] Lavie, J.C., Milani, V.R. and Ventura, O.H. (2009) Obesity and Cardiovascular Disease. JACC, 53, 1925-1932. http://dx.doi.org/10.1016/j.jacc.2008.12.068

[8] Kawakami, N., Akachi, K., Shimizu, H., Haratani, T., Kobayashi, F., Ishizaki, M., Hayashi, T., Fujita, O., Aizawa, Y., Miyazaki, S. and Hiro, H. (2000) Job Strain, Social Support in the Workplace, and Hemoglobin A1c in Japanese Men. Occupational and Environmental Medicine, 57, 805-809. http://dx.doi.org/10.1136/oem.57.12.805

[9] Li, J., Jarczok, M.N., Loerbroks, A., Siegrist, J., Chöllgen, I., Bosch, J.A., Wilson, M.G., Mauss, D. and Fischer, J.E. (2013) Work Stress Is Associated with Diabetes and Prediabetes: Cross-Sectional Results from the MIPH Industrial Cohort Studies. International Journal of Behavioral Medicine, 20, 495-503. http://dx.doi.org/10.1007/s12529-012-9255-0

[10] Kawakami, N., Araki, S., Takatsuka, N., Shimizu, H. and Ishimashi, H. (1999) Overtime, Psychosocial Working Conditions, and Occurrence of Non-Insulin Dependent Diabetes Mellitus in Japanese Men. Journal of Epidemiology \& Community Health, 53, 359-363. http://dx.doi.org/10.1136/jech.53.6.359

[11] Nishikido, N., Kageyama, T., Kobayashi, T. and Haratani, T. (2000) Evaluation of Occupational Stress by Simple Questionnaire-Information Processing Companies-The Association between Depression Score in Male Employees. Occupational Mental Health, 8, 73-82. (In Japanese with English Abstract)

[12] Gatineau, M., Hancock, C., Holman, N., Outhwaite, H., Oldridge, L., Christie, A. and Elis, L. (2014) Adult Obesity and Type 2 Diabetes, PHE Publications Gateway Number: 2014211.

https://www.gov.uk/government/uploads/system/uploads/attachment data/file/338934/Adult obesity and type 2 diab etes_pdf

[13] Taheri, S., Lin, L., Austin, D., Young, T. and Mignot, E. (2004) Short Sleep Duration Is Associated with Reduced Leptin, Elevated Ghrelin, and Increased Body Mass Index. PLoS Medicine, 1, e62. http://dx.doi.org/10.1371/journal.pmed.0010062

[14] Boyko, E.J., Seelig, A.D., Jacobson, I.G., Hooper, T.I., Smith, B., Smith, T.C., Crum-Cianflone, N.F. and Millennium Cohort Study Team (2013) Sleep Characteristics, Mental Health, and Diabetes Risk: A Prospective Study of US Military Service Members in the Millennium Cohort Study. Diabetes Care, 36, 3154-3161. http://dx.doi.org/10.2337/DC13-0042

[15] Chaput, J.P., Despres, J.P., Bouchard, C. and Tremblay, A. (2007) Short Sleep Duration Is Associated with Reduced Leptin Levels and Increased Adiposity: Results from the Quebec Family Study. Obesity, 15, 253-261. http://dx.doi.org/10.1038/oby.2007.512

[16] Gangwisch, J.E., Malaspina, D., Boden-Albala, B. and Heymsfield, S.B. (2005) Inadequate Sleep as a Risk Factor for Obesity: Analyses of the NHANES I. Sleep, 28, 1289-1296.

[17] Dashti, H.S., Scheer, F.A., Jacques, P.F., Lanon-Fava, S. and Ordovas, J.M. (2015) Short Sleep Duration and Dietary Intake: Epidemiologic Evidence, Mechanisms, and Health Implications. Advances in Nutrition, 6, 648-659. http://dx.doi.org/10.3945/an.115.008623

[18] Chan, J.C., Malik, V., Jia, W., Kadowaki, T., Yajnik, C.S., Yoon, K.H. and Hu, B.F. (2009) Diabetes in Asia: Epidemiology, Risk Factors, and Pathophysiology. JAMA, 301, 2129-2140. http://dx.doi.org/10.1001/jama.2009.726

[19] Tanabe, N., Seki, N., Aizawa, Y. and Suzuki, H. (2009) Association of Diagnostic Components of Metabolic Syndrome with Risk of Developing Diabetes Mellitus: Is Obesity Necessary for Prediction? Japanese Journal of Cardiovascular Disease Prevention, 44, 152-160. (In Japanese with English Abstract)

[20] Munakata, T. (2007) Knowing Your DNA Can Make Your Life More Scientific. Koudansha, Tokyo. (In Japanese) 


\section{Submit or recommend next manuscript to SCIRP and we will provide best service for you:}

Accepting pre-submission inquiries through Email, Facebook, LinkedIn, Twitter, etc.

A wide selection of journals (inclusive of 9 subjects, more than 200 journals)

Providing 24-hour high-quality service

User-friendly online submission system

Fair and swift peer-review system

Efficient typesetting and proofreading procedure

Display of the result of downloads and visits, as well as the number of cited articles

Maximum dissemination of your research work

Submit your manuscript at: http://papersubmission.scirp.org/ 